\title{
Improving oral and dental health through counseling, video and phantom demonstration during the Covid-19 pandemic to the Medan Belawan community
}

\author{
Trelia Boel $^{1 *}$, M. Zulkarnain ${ }^{2}$, Rini Octavia Nasution ${ }^{3}$, Lydia Irani Nainggolan ${ }^{1}$, Dewi \\ Kartika $^{1}$ \\ ${ }^{1}$ Departemen Radiologi Kedokteran Gigi, Faculty of Dentistry, Universitas Sumatera Utara \\ ${ }^{2}$ Departemen Prostodonsia, Faculty of Dentistry, Universitas Sumatera Utara \\ ${ }^{3}$ Departemen Periodonsia, Faculty of Dentistry, Universitas Sumatera Utara \\ *Email: treliaboel@gmail.com
}

\begin{abstract}
Based on Basic Health Research, dental and oral diseases still occur in the province of North Sumatra, both urban and rural. Through the USU Community Service Institute, community service activities are carried out with the title of improving oral and dental health through counseling and maintenance of oral health in the Medan Belawan community. This activity is based on the need to maintain oral and dental health from an early age, so that good behavior in maintaining health can be accustomed from a young age. Implementation of counseling on Improving Dental and Oral Health during the Covid-19 Pandemic to the Medan Belawan community, totaling 67 people, activities are carried out within 1 (one) day. Extension methods and techniques include video screenings, lectures, demonstrations of phantoms in oral and dental care and question and answer sessions. The results achieved are that it is necessary to carry out further dedication to the school environment in Medan Belawan for Health Education and Maintenance during the Covid-19 Pandemic.
\end{abstract}

Keyword: Oral and dental health, counseling, video demonstration, phantom demonstration

\begin{abstract}
Abstrak
Berdasarkan Riset Kesehatan Dasar, penyakit gigi dan mulut masih terjadi di provinsi Sumatera Utara baik perkotaan maupun pedesaan. Melalui Lembaga Pengabdian pada Masyarakat USU, dilakukan kegiatan pengabdian dengan judul peningkatan kesehatan gigi dan mulut melalui penyuluhan dan pemeliharaan kesehatan gigi dan mulut pada komunitas masyarakat Medan Belawan. Kegiatan ini didasarkan atas perlunya memelihara kesehatan gigi dan mulut sejak dini, agar perilaku yang baik dalam menjaga kesehatan dapat dibiasakan dari kecil. Pelaksanaan penyuluhan Peningkatan Kesehatan Gigi dan Mulut di Masa Pandemik Covid-19 pada masyarakat Medan Belawan yang berjumlah 67 orang, Kegiatan dilakukan dalam waktu 1(satu) hari. Metode dan teknik penyuluhan meliputi pemutaran video, ceramah, demonstrasi phantom dalam pemeliharaan gigi dan mulut dan sesi tanya jawab. Hasil yang dicapai adalah perlu dilaksanakan pengabdian lebih lanjut ke lingkungan sekolah di Medan Belawan untuk Penyuluhan dan Pemeliharan Kesehatan Gigi dan Mulut di Masa Pandemik Covid-19.
\end{abstract}

Kata Kunci: Kesehatan gigi dan mulut, penyuluhan, demonstrasi video, demonstrasi phantom

\section{PENDAHULUAN}

Menurut WHO, kesehatan gigi dan mulut merupakan bagian yang sangat penting dari kesehatan secara umum dan berpengaruh terhadap kesejahteraan. Kesehatan gigi dan mulut yang buruk dapat mengakibatkan terganggunya kualitas hidup (Jürgensen and Petersen, 2009). Oleh sebab itu, sangat penting menjaga rongga mulut dan gigi agar senantiasa selalu sehat dengan selalu menjaga kebersihannya (Bangash et al., 2012). Rongga mulut dan gigi yang bersih membuat orang merasa lebih percaya diri untuk berbicara, makan, dan bersosialisasi tanpa rasa sakit, tidak nyaman ataupun rasa malu (Kwan et al., 2005).

Tindakan pencegahan yang paling utama agar gigi tidak rusak adalah dengan menjaga kebersihan gigi dan mulut setiap hari dengan benar. Agar kebersihan gigi dan mulut dapat selalu 
terjaga dengan baik, maka tindakan yang paling banyak dianjurkan dan dilaksanakan adalah menyikat gigi (Asadoorina, 2006). Menyikat gigi secara teratur merupakan metode utama untuk menghilangkan plak serta mengontrol penyakit akibat plak, seperti karies dan periodontitis (Gallagher, 2009).

Hasil Riskesdas 2013 tentang kesehatan gigi dan mulut yaitu prevalensi nasional masalah gigi dan mulut adalah 25,9 persen, sebanyak 14 provinsi mempunyai prevalensi masalah gigi dan mulut diatas angka nasional. Prevalensi nasional menyikat gigi setiap hari adalah 94,2 persen sebanyak 15 provinsi berada dibawah prevalensi nasional. Untuk perilaku benar dalam menyikat gigi berkaitan dengan faktor gender, ekonomi, dan daerah tempat tinggal. Ditemukan sebagian besar penduduk Indonesia menyikat gigi pada saat mandi pagi maupun mandi sore, $(76,6 \%)$. Menyikat gigi dengan benar adalah setelah makan pagi dan sebelum tidur malam, untuk Indonesia ditemukan hanya 2,3 persen ( Riskesdas 2013).

Pentingnya pendidikan terkait menjaga kesehatan gigi dan mulut yang dilakukan secara terus menerus memberikan hasil yang baik. Pencegahan serta promosi kesehatan gigi dan mulut harus dilakukan sedini mungkin untuk mencegah timbulnya masalah gigi dan mulut (Deljo et al., 2011). Kebiasaan dan gaya hidup yang dikembangkan saat usia muda akan lebih melekat karena pesan pesan yang diperoleh dapat semakin diperkuat selama mereka masih dalam masa sekolah (Kwan et al., 2005).

Di Sumatera Utara, prevalensi masalah gigi dan mulut sebesar 19,4\%. Saat umur sudah lebih dari satu tahun dimana gigi geligi mulai tumbuh, maka persentase masalah gigi dan mulut terus meningkat. Penyakit gigi dan mulut dapat terjadi baik di perkotaan maupun di pedesaan, dengan prevalensi sebesar 26\% dan 25,9\%. Perbedaan tersebut tidak begitu jauh. Di perkotaan, ketersediaan dokter gigi lebih besar dibandingkan di pedesaan, sehingga perawatan gigi di perkotaan lebih baik dibandingkan pedesaan. Oleh sebab itu sangat penting dilakukan pencegahan sedini mungkin agar terhindar dari masalah penyakit gigi dan mulut (Riskesdas 2015).

Kesehatan sangat penting untuk selalu diperhatikan. Perilaku yang sehat dapat mempengaruhi kesehatan tubuh setiap orang. Kesehatan gigi dan mulut merupakan bagian dari kesehatan secara umum. Untuk tetap menjaga gigi dan mulut tetap sehat dapat dilakukan dengan selalu menjaga kebersihan gigi dan mulut setiap hari. Hal yang paling mudah dilakukan yaitu dengan cara menyikat gigi dan mencuci tangan sebelum makan. Teknik dan cara menyikat gigi yang benar sangat mempengaruhi kebersihan gigi.

Berdasarkan Riset Kesehatan Dasar, penyakit gigi dan mulut masih terjadi di provinsi Sumatera Utara baik perkotaan maupun pedesaan. Oleh sebab itu melalui Lembaga Pengabdian pada Masyarakat USU dilakukan kegiatan pengabdian dengan judul peningkatan kesehatan gigi dan mulut melalui penyuluhan dan pemeliharaan kesehatan gigi dan mulut pada komunitas masyarakat Medan Belawan. Kegiatan ini didasarkan atas perlunya memelihara kesehatan gigi dan mulut sejak dini, agar perilaku yang baik dalam menjaga kesehatan dapat dibiasakan dari kecil. Selain itu masih belum banyak anggota masyarakat yang belum menyadari dengan benar akan pentingnya kesehatan gigi untuk kesehatan secara umum.

\section{METODE PELAKSANAAN}

Kegiatan pengabdian kepada masyarakat ini dilaksanakan oleh 5 orang tim pengabdi yang berasal dari Fakultas Kedokteran Gigi Universitas Sumatera Utara pada tanggal 23 September 2020, mulai dari jam 9.00 AM - jam 3.00 PM. Selain itu, tim pengabdian melibatkan 15 orang mahasiswa yang ikut membantu melakukan demonstrasi terhadap masyarakat Belawan.

Hasil analisis dan wawancara pendahuluan dengan pimpinan organisasi kemasyarakatan diperoleh data bahwa banyak masyarakat yang mengalami gigi karies, atau berlubang. Selain itu banyak juga masyarakat yang mengeluhkan gusi bengkak dan berdarah. Ini menandakan, bahwa sudah terjadi peradangan gusi yang disebabkan oleh plak dan kalkulus.

Pelaksanaan penyuluhan Peningkatan Kesehatan Gigi dan Mulut di Masa Pandemik Covid-19 pada masyarakat Medan Belawan yang berjumlah 67 orang, Kegiatan dilakukan dalam waktu 1(satu) 
hari. Metode dan teknik penyuluhan meliputi pemutaran video, ceramah, demonstrasi pemeliharaan gigi dan mulut dan sesi tanya jawab. Bentuk kegiatan pengabdian yang dilakukan adalah bentuk penyulihan peningkatan kesehatan gigi dan mulut. Susunan kegiatan penyuluhan adalah sebagai berikut:

1. Persiapan acara pengabdian masyarakat.

2. Pembukaan yang dilakukan oleh pelaksana pengabdian

3. Penyampaian materi dengan metode ceramah yang dibantu dengan pemutaran video

4. Demonstrasi pemeliharaan gigi dan mulut

5. Sesi tanya jawab dengan masyarakat

6. Penutupan

\section{HASIL DAN PEMBAHASAN}

Kegiatan pengabdian masyarakat ini dimulai dengan survey awal terkait lokasi dan sasaran pengabdian kepada masyarakat. Peserta yang terlibat dalam kegiatan ini adalah masyarakat Medan Belawan. Kegiatan penyuluhan ini berjalan dengan baik dan lancar. Masyarakat sangat antusias terhadap kegiatan yang dilakukan. Penyampaian materi dilaksanakan langsung oleh ketua pelaksana pengabdian masyarakat dengan bantuan video.

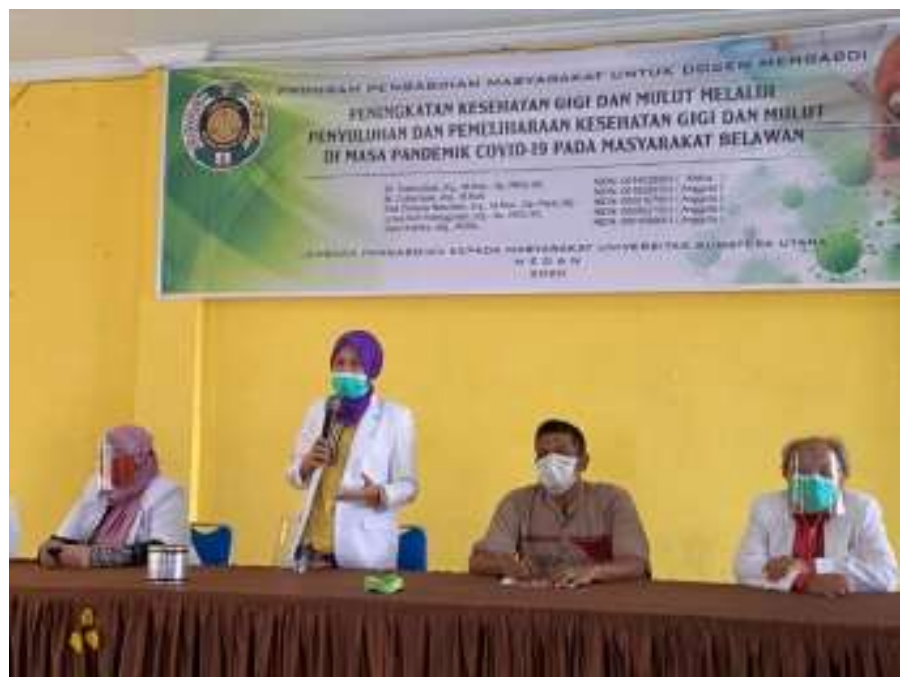

\section{Gambar 3.1. Ketua Pengabdian Kepada Masyarakat memberikan penyuluhan}

Penyampaian materi dilakukan sekitar 45 menit. Materi penyuluhan meliputi tata cara pemeliharaan kesehatan gigi dan mulut, pengarahan tentang makanan dan minuman yang sehat, dan pemeliharaan dengan berkunjung ke dokter gigi. Kegiatan dilanjutkan dengan demonstrasi pemeliharaan gigi dan mulut, dan tanya jawab dengan masyarakat. 


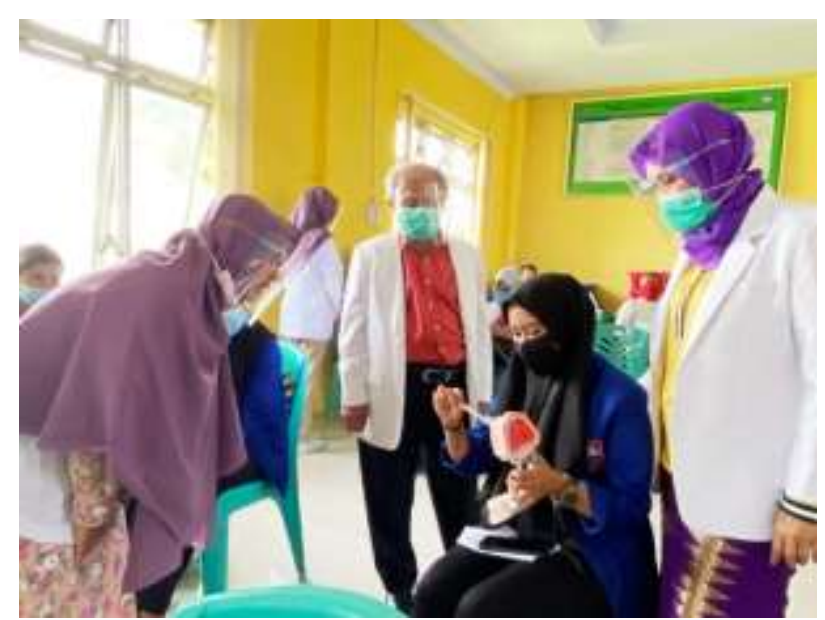

Gambar 3.2. Masyarakat sedang melaksanakan cara sikat gigi yang baik dan benar

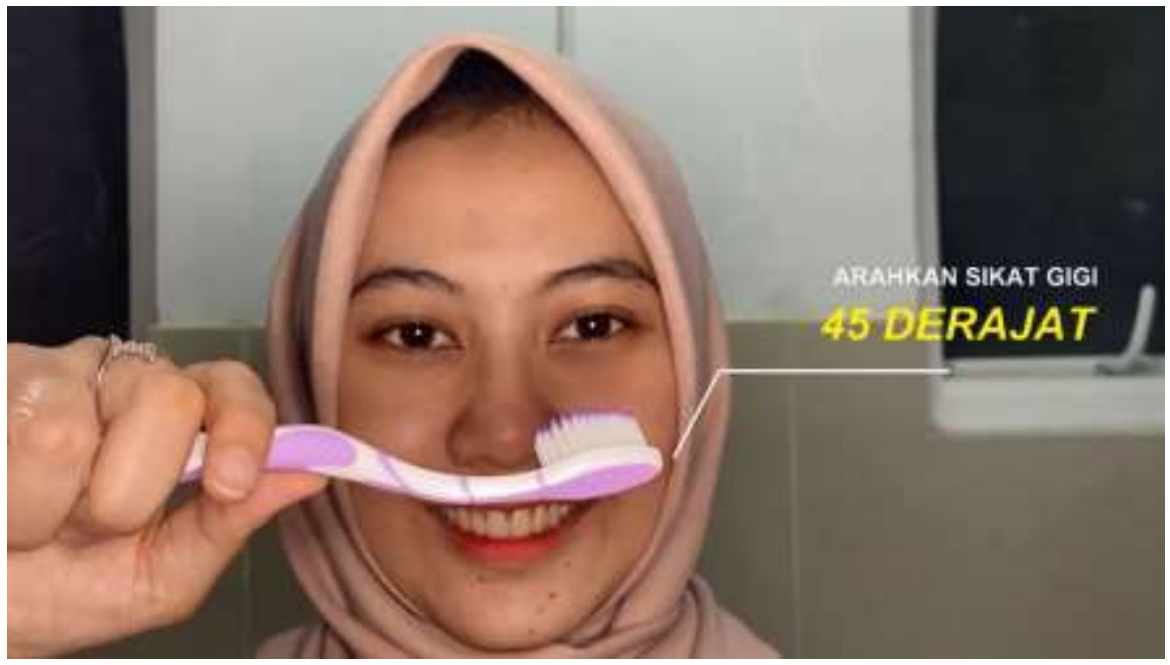

Gambar 3.3 Konten demonstrasi video

Di dalam pengarah, waktu terpenting menyikat gigi adalah setelah sarapan di pagi hari dan sebelum tidur saat malam hari. Adapun langkah-langkah menyikat gigi yang benar adalah:

a. Pilih sikat gigi dengan bulu sikat yang soft/lembut dan pasta gigi yang mengandung fluoride

b. Basahi sikat gigi dan letakkan pasta gigi secukupnya

c. Arahkan sikat gigi sebesar $45^{\circ}$ atau sedikit miring terhadap gigi, tindakan ini agar bulu sikat sedikit masuk ke leher gusi sehingga sisa makanan yang terdapat pada gusi pun dapat dibersihkan.

d. Gerakkan sikat gigi dengan gerakan memutar pada gigi, pastikan semua permukaan gigi tersikat dengan baik. Lakukan gerakan ini secara berulang

e. Jangan menyikat gigi terlalu kuat dan keras, karena dapat melukai jaringan disekitar gigi (gusi)

f. Menyikat gigi dilakukan selama \pm 2 menit

g. Setelah menyikat semua gigi, sikat juga permukaan lidah dengan gerakan searah (karena struktur lidah yang berlekuk-lekuk dapat membuat sisa makanan terperangkap)

h. Kumur-kumur jika sudah selesai.

Pola makan yang seimbang dan bergizi penting untuk kesehatan mulut dan kesehatan umum yang baik. Makanan yang kita konsumsi memberikan nutrisi yang dibutuhkan tubuh, tulang, gigi, 
dan gusi untuk memperbarui jaringan dan membantu melawan infeksi dan penyakit. Makanan dan minuman yang baik untuk Kesehatan gigi dan mulut adalah sebagai berikut :

a. Makanan yang berasal dari susu, seperti :

Susu, keju daan yoghurt mengandung nutrisi seperti Kalsium, Casein serta Phospor yang dapat meningkatkan kekuatan gigi dan tulang

b. Sayuran dan buah-buahan

- Buah-buahan dan sayur yang kaya akan Vitamin C seperti jerukdan tomat; dapat membantu melindungi gusi dan jaringan lain dari kerusakan sel dan infeksi bakteri.

- Broccoli dan sayuran hijau : mengandung vitamin $\mathrm{K}$ yang dapat membantu pembentukan protein yang dibutuhkan untuk kekuatan tulang dan gigi

- Buah-buahan dan sayuran lainnya seperti apel, pear, wortel dan timun dapat membantu membersihkan gigi dari partikel makanan selama proses mengunyah. Makanan ini meningkatkan aliran air liur, yang membantu membilas gigi dari partikel makanan

c. Biji-bijian utuh seperti:

Sereal dan kacang-kacangan kaya akan Kalsium, Phospor, Magnesium, vitamin K (terutama K2) dan vitamin D dimana vitamin dan mineral ini baik untuk kekuatan tulang dan gigi.

d. Kuning telur dan ikan ; mengandung vitamin D yang dapat membantu tubuh dalam menyerap kalsium.

e. Seafood, daging merah dan hati ayam: mengandung mineral Zinc yang dapat meningkatkan kekuatan tulang serta menjaga kolagen tubuh.

Daging merah juga mengandung zat besi yang dapat mencegah radang pada lidah.

Kebiasaan menjaga kebersihan mulut dan gigi memang perlu dipelihara seumur hidup. Namun, akan lebih bagus lagi jika kamu mengimbanginya dengan tidak mengonsumsi minuman dan makanan yang dapat merusak gigi. Beberapa jenis makanan dan minuman di bawah ini tanpa disadari dapat merusak gigi.

\section{a. Makanan/Minuman Asam yang Tinggi}

Makanan atau minuman yang terasa sangat asam sangat berbahaya untuk gigi kamu, karena dapat mengikis email gigi dan menyebabkan gigi berlubang. Pelemahan email gigi ini juga dapat menyebabkan masalah sensitivitas hingga perubahan warna gigi. Makanan yang memiliki asam tinggi di antaranya lemon, acar, tomat, alkohol, dan kopi.

\section{b. Tinggi Gula}

Terlalu banyak mengonsumsi makanan dan minuman terlalu manis bukan hanya buruk untuk kesehatan tubuh, tetapi juga berdampak buruk bagi kesehatan mulut. Perlu diketahui, bakteri di dalam mulut memakan gula untuk menciptakan asam. Di samping itu, infeksi dalam rongga mulut berkaitan erat dengan kadar asam.

Meski sulit dihindari untuk konsumsi sehari-hari, kamu harus berusaha mengurangi asupan gula (terutama gula rafinasi) sebanyak mungkin. Contoh makanan dan minuman tinggi gula adalah soft drinks, permen, buah kering, makanan penutup, selai, dan sereal.

\section{c. Makanan Lengket/Kenyal}

Makanan dan minuman lengket biasanya akan menempel dan melekat pada gigi atau gusi dalam waktu lama. Sisa makanan inilah yang menjadi pemicu munculnya bakteri jahat. Hal ini tentunya akan memungkinkan bakteri memproduksi lebih banyak asam dari biasanya. Flossing gigi merupakan cara yang ampuh untuk menghilangkan makanan lengket yang melekat di dalam rongga mulut kamu.

\section{d. Makanan Bertepung/Olahan}

Ketika kamu mengonsumsi makanan karbohidrat olahan, makanan tersebut akan berubah menjadi gula di dalam mulut. Saat itu pula produksi asam akan dimulai oleh bakteri jahat. Roti putih, keripik kentang, dan pasta merupakan beberapa makanan bertepung yang dapat dengan mudah tersangkut di antara gigi. Perlu dicatat bahwa tepung mulai berkonversi menjadi gula dengan segera melalui proses pra-pencernaan yang dimulai di mulut melalui enzim dalam air liur. 


\section{e. Alkohol}

Mengonsumsi alkohol akan membuat mulut kering dan dehidrasi. Padahal, air liur dibutuhkan mulut untuk membersihkan diri dari sisa-sisa makanan dan melindungi jaringan lunak di mulut dari iritasi dan infeksi. Mulut kering menjadi sumber penyakit karena dapat mendorong kuman untuk berkembang biak. Kebiasaan ini nantinya akan menjadi akar masalah kerusakan gigi dan infeksi mulut lainnya.

\section{f. Minuman Bersoda}

Selain mengandung gula yang sangat tinggi, soda juga dapat membuat mulut menjadi kering. Kondisi ini menjadi tempat bagi bakteri jahat untuk berkembang biak. Minuman soda berwarna juga dapat merusak warna asli gigi. Akibatnya, gigi kamu akan terlihat lebih gelap dan kusam.

Hal yang perlu diperhatikan adalah kamu jangan langsung menyikat gigi setelah mengonsumsi minuman bersoda, karena aktivitas ini malah mempercepat pembusukan. Langkah terbaik adalah berkumur dan minum banyak air putih.

\section{g. Mengunyah Es Batu}

Meskipun terlihat sepele, nyatanya kebiasaan mengunyah es batu dapat merusak gigi kamu. Mengunyah zat keras seperti es batu dapat merusak email gigi dan membuat gigi kamu lebih sensitif. Dampak lainnya adalah mengunyah es batu berisiko membuat gigi kamu longgar dan rentan tanggal.

Nah, itulah jenis makanan dan minuman yang dapat membuat gigi berlubang dan perlu kamu hindari. Agar kesehatan gigi dan mulut kamu terjaga baik, kamu perlu rutin memeriksakan gigi ke dokter setiap 6 bulan sekali.

\section{KESIMPULAN}

Dari hasil kegiatan pengabdian kepada masyarakat yang telah dilaksanakan oleh tim pengabdi dapat disimpulkan bahwa

1. Pelaksanaan kegiatan penyuluhan peningkatan kesehatan gigi dan mulut di masa pandemic COVID-19, dalam kalangan masyarakat Medan Belawan dengan jumlah 67 orang

2. Kegiatan pengabdian masyarakat ini bertujuan untuk meningkatkan kesadaran akan pentingnya perawatan gigi dan rongga mulut.

3. Upsus peningkatan kesehatan gigi dan mulut ini dapat dilakukan peserta pengabdian dengan cara menyikat gigi secara teratur, mengkonsumsi makanan dan minuman yang sehat dan pemeriksaan ke dokter gigi secara teratur

Adapun yang menjadi saran pada pengabdian masyarakat selanjutnya adalah perlu dilaksanakan pengabdian lebih lanjut ke lingkungan sekolah di Medan Belawan untuk Penyuluhan dan Pemeliharan Kesehatan Gigi dan Mulut di Masa Pandemik Covid-19

\section{UCAPAN TERIMAKASIH}

Artikel ini merupakan salah satu hasil dari Program Pengabdian kepada Masyarakat yang dibiayai oleh dana NON PNBP Universitas Sumatera Utara. oleh karena itu, diucapkan terimakasih kepada Rektor USU dan LPPM USU yang telah memberikan dana pengabdian tahun 2020 Skema Profesor mengabdi. Terima kasih juga kepada Forum Masyarakat Medan-Belawan pada kegiatan pengabdian ini. 


\section{DAFTAR PUSTAKA}

Asadoorina, J., 2006, Tooth Brushing, Canadian Journal of Dental Hygiene (CJDH), 40(5): 1-14.

Bangash, R.Y., Khan, A. U., Tariq,K. M., and Dil, R., 2012, Evaluation of Tooth Brushing Technique and Oral Hygiene Knowledge at Afid, Rawalpindi, Pakistan Oral \& Dental Journal, 32(1):124-127.

Deljo, E., Barbacic, R., Meskovic, B., and Grabus, J., 2011, Impact of Continous Education About Oral hygiene on the Changes of CPI-index for 12-15 Year Old Schoolchildren, Acta Inform med, 19(4):220-223.

Departemen Kesehatan Republik Indonesia, Data laporan nasional riset kesehatan dasar, 2013.

Gallagher, A., Sowinski, J., Bowman, J., Barrett, K., Lowe, S., Patel, K., Bosma, M. L., and Creeth, J. E., 2009, The Effect of Brushing Time and Dentifrice on Dental Plaque Removal in vivo. The Journal of Dental Hygiene, 83(3):111-116.

Jürgensen, N., and Petersen, P.E., 2009, Oral Health and The Impact of Socio- Behavioral factors in a Cross Sectional Survey of 12-year Old School Children in Laos, Biomed Central Oral Health, 9 (29):1-11.

Kwan, S.Y.L., Petersen, P.E., Pine, C.M., and Borutta, A., 2005, HealthPromoting Schools: an Apportunity for Oral Health Promotion, Bulletin of the World Health Organization, 83(9): 677-685. 